\title{
BACE1 activity regulates cell surface contactin-2 levels
}

\author{
Vivek Gautam, Carla D'Avanzo, Matthias Hebisch, Dora M Kovacs and Doo Yeon Kim*
}

\begin{abstract}
Background: Although BACE1 is a major therapeutic target for Alzheimer's disease (AD), potential side effects of BACE1 inhibition are not well characterized. BACE1 cleaves over 60 putative substrates, however the majority of these cleavages have not been characterized. Here we investigated BACE1-mediated cleavage of human contactin-2, a GPI-anchored cell adhesion molecule.

Results: Our initial protein sequence analysis showed that contactin-2 harbors a strong putative BACE1 cleavage site close to its GPI membrane linker domain. When we overexpressed BACE1 in CHO cells stably transfected with human contactin-2, we found increased release of soluble contactin-2 in the conditioned media. Conversely, pharmacological inhibition of BACE1 in CHO cells expressing human contactin-2 and mouse primary neurons decreased soluble contactin-2 secretion. The BACE1 cleavage site mutation 1008MM/AA dramatically impaired soluble contactin-2 release. We then asked whether contactin-2 release induced by BACE1 expression would concomitantly decrease cell surface levels of contactin-2. Using immunofluorescence and surface-biotinylation assays, we showed that BACE1 activity tightly regulates contactin-2 surface levels in $\mathrm{CHO}$ cells as well as in mouse primary neurons. Finally, contactin-2 levels were decreased in Alzheimer's disease brain samples correlating inversely with elevated BACE1 levels in the same samples.

Conclusion: Our results clearly demonstrate that mouse and human contactin-2 are physiological substrates for BACE1. BACE1-mediated contactin-2 cleavage tightly regulates the surface expression of contactin-2 in neuronal cells. Given the role of contactin-2 in cell adhesion, neurite outgrowth and axon guidance, our data suggest that BACE1 may play an important role in these physiological processes by regulating contactin-2 surface levels.
\end{abstract}

\section{Introduction}

Alzheimer's disease (AD) is the most common neurodegenerative disease that affects millions of people worldwide. Studies strongly suggest that the accumulation of toxic amyloid $-\beta$ peptides $(A \beta)$ is associated with synaptic dysfunction and neuronal loss in $\mathrm{AD}[1]$. $\mathrm{A} \beta$ peptides are generated from sequential cleavages of the amyloid $\beta$ precursor protein (APP), which are mediated by the $\beta$-site APP cleaving enzyme 1 (BACE1) and Presenilin $/ \gamma$-secretase [2-4]. Therefore, BACE1 and $\gamma$-secretase represent two major therapeutic targets for prevention and treatment of AD.

BACE1, also known as memapsin 2 and Asp 2, is a type I transmembrane aspartyl protease that is highly

\footnotetext{
* Correspondence: dora_kovacs@hms.harvard.edu; dkim@helix.mgh.harvard.edu Genetics and Aging Research Unit, MassGeneral Institute for

Neurodegenerative Disease, Massachusetts General Hospital, Harvard Medical School, Charlestown, MA 02129, USA
}

\section{Biomed Central}

expressed in neuronal tissues [5,6]. Besides generating pathogenic $A \beta, B A C E 1$ also plays crucial roles in numerous physiological processes including neuronal activity, myelination, axonal guidance, presynaptic activity and cognitive behavior in mice [7-14]. These physiological BACE1 functions cast a doubt on the safety of BACE1 inhibition therapy currently being developed to block $A \beta$ generation in $\mathrm{AD}$ patients. Currently more than 60 BACE1 substrates have been reported in in vitro and in vivo conditions [15-21]. Therefore characterizing BACE1-mediated cleavage for each substrate may not only contribute to our understanding of how BACE1 regulates crucial physiological processes but also aid in the prevention of potential side effects deriving from BACE1 inhibition therapy.

Contactin-2 (axonin-1 or transient axonal glycoprotein1 (TAG-1)) is a cell adhesion molecule that belongs to immunoglobulin super family [22,23]. Contactin-2 is highly 
expressed at the axon growth cone and plays an important role in regulating axon guidance and path finding $[24,25]$. Studies from knockout mice revealed that contactin-2 is also crucial for normal learning and memory functions [26]. While the majority of currently reported BACE1 substrates are type I membrane proteins with transmembrane domains, contactin-2 belongs to the carboxy-terminal glycan phosphatidyl inositol (GPI)-anchored protein family that requires covalent linkage of GPI domains for binding to the plasma membrane. Interestingly, two recent unbiased secretome analyses suggested that BACE1 activity regulates the release of contactin- 2 in neurons but the BACE1-mediated contactin-2 cleavage has not been fully characterized $[19,20]$. Therefore we decided to characterize BACE1-mediated cleavage of contactin-2 in cellular and neuronal models and explore whether BACE1 cleavage regulates surface expression of contactin-2, potentially affecting the cell adhesion function of the protein.

\section{Materials and methods Antibodies and reagents}

Anti-human contactin-2 (MAB-1714) and anti-mouse contactin-2 (AF4439) antibodies were purchased from R\&D Systems (Minneapolis, USA). The rabbit monoclonal anti-human contactin-2 antibody was from Abcam (Cambridge, USA) while rabbit monoclonal BACE1 antibody was from Cell Signaling Inc. (Boston, USA). Anti-mouse V5 antibody was from Life Technologies (Grand Island, USA). Rabbit anti-APP was described earlier [27]. sAPP (22C11), N-cadherin and NrCAM antibodies were from EMD Millipore (Billerica, USA). BACE1 Inhibitor IV was also purchased from EMD Millipore.

\section{Plasmid construction}

Human contactin-2 plasmid (MGC:157722) was obtained from Harvard Plasmid DNA Resource Core (Harvard Medical School, Boston). Contactin-2 cDNA coding region was amplified using the following primers: forward, CACCATGGGGACAGCCACCAGG AGG; reverse, TCAGAGCTCCAGGGAGCCTATGAGG. The amplified fragments were subcloned into pcDNA6.1 vector (directed TOPO system, Life Technologies). For generation of the soluble form of contactin-2, a V5-tag was C-terminally added to inactivate the GPI-anchor domain. The putative BACE1 cleavage site was mutated in the contactin-2 cDNA construct (CNTN2-MM1008AA) with the help of Quick Change site-directed mutagenesis kit from Agilent Technologies (Santa Clara, USA) according to the manufacturer's protocol using the following primers: forward, GAGGAATGGAGGCACAAGCGCGG CGGTGGAGAACATGGCAGTC; reverse, GACTGCC ATGTTCTCCACCGCCGCGCTTGTGCCTCCATTC CTC. All the constructs were sequenced and verified at the MGH DNA sequencing core facility (Boston, USA).

\section{Generation of contactin-2 stable cell lines}

Single cell stable lines were generated for both GPIanchored contactin-2 and soluble contactin-2 (V5-tagged) in $\mathrm{CHO}$ cells. Briefly, $4 \mu \mathrm{g}$ of GPI-anchored contactin-2 and soluble contactin-2 cDNA were transfected in $\mathrm{CHO}$ cells with the help of Effectene transfection reagent (Qiagen, Valencia, USA) according to the manufacture's protocol. $48 \mathrm{~h}$ after transfection, cells were trypsinized and replated in the presence of $10 \mu \mathrm{g} / \mu \mathrm{l}$ of Blasticidin selection marker. After 2 weeks of selection, Blasticidin resistant cells were further plated in serial dilutions in a 96-well plate in order to get single cell colonies. Later, different single cell clones were picked and analyzed by Western blotting for the optimal expression of contactin2 with the help of specific antibodies.

\section{Primary neuronal cultures}

Primary neuronal cultures were prepared from 16-day old pregnant female mice (CD-1). Mice were purchased from Charles River Laboratories, Cambridge, and the animal protocol was approved by the MGH Institutional Animal Committee. In brief, hippocampi and frontal cortices were dissected and isolated from pups at embryonic day 16 (E-16). Dissected tissue was further triturated using fine pasture pipette and later plated on polyD-lysine/laminin coated 6-well tissue culture plate using Neurobasal media containing 2\% B-27 serum supplement (Life Technologies). Cultures were maintained in a humidified environment at $37^{\circ} \mathrm{C}$ with $5 \% \mathrm{CO}_{2}$ and $50 \%$ of the media were replaced every $3^{\text {rd }}$ day.

\section{Lentiviral generation and infection}

BACE1 and the control mCherry lentiviral particles were generated at the MGH Vector Core facility (Charlestown, USA). Contactin- 2 expressing $\mathrm{CHO}$ cells at $40 \%$ confluency were infected with $1 \times 10^{6}$ lentiviral particles. $24 \mathrm{~h}$ after infection, media was replaced and the cells were allowed to grow for a total of 5 days before extraction. In case of primary neurons, cultures were infected at DIV5 with $1 \times 10^{6}$ lentiviral particles. In order to reduce the lentivirus-mediated toxicity, $50 \%$ of the culture media was replaced $12 \mathrm{~h}$ after infection. Cultures were allowed to grow for 6 additional days after infection.

\section{BACE1 inhibitor treatment}

CHO cells stably expressing GPI-anchored contactin-2 were plated on $60 \mathrm{~mm}$ tissue culture plate and treated with either $4 \mu \mathrm{M}$ of BACE1 Inhibitor IV (EMD Millipore) or the same volume of DMSO control vehicles. The treated cells were allowed to grow for $48 \mathrm{~h}$ and the media was replaced with fresh media containing BACE1 Inhibitor IV. $48 \mathrm{~h}$ after conditioning, both the media and the cells were collected, processed and analyzed by Western blot. For primary neuronal cultures, the neurons were 
treated with $1 \mu \mathrm{M}$ BACE1 Inhibitor IV for $48 \mathrm{~h}$, replaced with fresh media containing $1 \mu \mathrm{M}$ of BACE1 Inhibitor IV, and then incubated for additional $48 \mathrm{~h}$ before collecting the media and the cells.

\section{Western blot analysis}

Cells were lysed in 1X GTIP buffer containing $10 \mathrm{mM}$ Tris- $\mathrm{HCl}$ (pH 6.8), 2 mM EDTA (pH 8.0), $150 \mathrm{mM}$ $\mathrm{NaCl}, 1 \%$ Triton $\mathrm{X}-100,0.25 \%$ Nonidet P-40, and a protease inhibitor cocktail (Roche Molecular Biochemicals, Indianapolis, IN, USA). The lysates were centrifuged at $16,000 \times \mathrm{g}$ in order to remove insoluble materials and the protein concentration was measured using a BCA protein assay kit (Pierce Biotechnology, Rockford, USA). 25-75 $\mu$ g protein samples were separated either on $3-8 \%$ Tris-Acetate gels, 4-12\% gradient Bis-Tris gels, or $12 \%$ Bis-Tris gels (Life Technologies) and transferred on PVDF membrane. Blots were then blocked either with $5 \%$ skimmed milk or with 5\% BSA (Sigma, St. Louis, MO, USA) for overnight at $4^{\circ} \mathrm{C}$. Primary antibodies were used at the following dilutions: human contactin-2 (1:200), mouse contactin-2 (1:200), anti-V5 (1:3000), anti-APP C-66 (1:1000), anti-BACE1 (1:1000), antisAPP $\beta$ (1:200), anti-N-cadherin (1:1000), anti-NrCAM (1:1000) and anti-GAPDH (1:2000). Blots were developed by chemiluminescence using Biomax light film (Kodak, Rochester, USA) or Versa Doc imaging system and quantified using Quantity One software (Biorad).

\section{Immunofluorescence analysis}

CHO cells stably expressing GPI-anchored contactin-2 were plated on glass coverslips in a 6-well tissue culture plate. Cells were treated with $4 \mu \mathrm{M}$ BACE1 Inhibitor IV or DMSO for $48 \mathrm{~h}$, fixed and then stained with anti-human contactin-2 antibody (1:200) without permeabilization for overnight at $4^{\circ} \mathrm{C}$. After incubating with Alexa Fluor488-conjugated secondary antibody, cover slips were mounted on the glass slides with the help of mounting media containing DAPI (Life Technologies). Images were taken on Olympus IX 70 microscope with the same exposure settings and later processed by IPLab software.

\section{Cell surface biotinylation}

Cell surface biotinylation experiments were performed on primary neuronal cultures at day 15 (DIV15). Cultures grown in 6-well plate were washed three times with ice cold Hank's balanced salt solution (HBSS) and incubated in dark for $1 \mathrm{~h}$ with $2 \mathrm{ml}$ of ice cold HBSS containing $0.5 \mathrm{mg} / \mathrm{mL}$ Sulfo-NHS-Biotin (Pierce). Fiveminute incubation with $100 \mu \mathrm{M}$ lysine solution was used to quench the reaction followed by three washes with cold HBSS. Cells were then extracted directly in an extraction buffer containing $10 \mathrm{mM}$ Tris- $\mathrm{HCl}(\mathrm{pH}$ 6.8),
2 mM EDTA (pH 8.0), $150 \mathrm{mM} \mathrm{NaCl}, 1 \%$ Triton $\mathrm{X}-100$, 0.5\% Sodium Deoxycolate, 0.2\% SDS, $1 \mathrm{mM}$ PMSF, 20 $\mu \mathrm{M}$ ALLN and a protease inhibitor cocktail (Roche Molecular Biochemicals). The insoluble fractions were removed by centrifugation at $16,000 \times \mathrm{g}$ and the protein concentrations were determined using the BCA protein assay kit (Pierce). 200-600 $\mu$ g of protein was immunoprecipitated using NeutrAvidin beads (Pierce) overnight at $4^{\circ} \mathrm{C}$. Next day, samples were washed 3 times with the extraction buffer, eluted with the LDS sample loading buffer (Life Technologies) supplemented with 2\% (v/v) $\beta$-mercaptoethanol and separated on $4-12 \%$ Bis TrisAcetate NuPage gel (Life Technologies) followed by Western blot analysis using various primary antibodies.

\section{Analysis of $A D$ brain samples}

Brain samples from 9 AD and 8 Non-AD patients (agematched, temporal lobe region) were obtained from Dr. Yong Shen (Roskamp Institute, Sarasota, FL). The same set of samples were previously used to analyze altered sodium channel metabolism [16]. Frozen tissue samples were lysed with extraction buffer containing $10 \mathrm{mM}$ Tris- $\mathrm{HCl}$ (pH 6.8), 1 mM EDTA, $150 \mathrm{mM} \mathrm{NaCl}, 0.25 \%$ Nonidet P-40, 1\% Triton X-100, 0.2\% SDS and a protease inhibitor cocktail (Roche Molecular Biochemicals). $75 \mu \mathrm{g}$ of protein was resolved on $12 \%$ Bis/Tris NuPage gels or 3-8\% Tris/Acetate gels. BACE1 levels were determined in our previous study [16] while amyloid plaque density information for individual samples were provided by Dr. Shen's laboratory.

\section{Results and discussion}

\section{Contactin-2 is a substrate for BACE1}

To investigate the physiological functions mediated by BACE1, we have been identifying novel substrate proteins other than APP $[10,16,21]$. Toward this goal, we used an unbiased bioinformatics approach and identified a group of candidate substrate proteins that contain putative BACE1 cleavage sites close to the cell membrane. Interestingly, both human and mouse contactin-2 harbor a strong putative BACE1 cleavage site in their extracellular $\mathrm{NH}_{2}$-terminal domain 4 amino acids upstream from its GPI membrane linker (Figure 1A). Two previous reports have also suggested that mouse contactin- 2 may be a BACE1 substrate $[19,20]$.

To test whether contactin-2 is a BACE1 substrate in cells, we first generated expression constructs with fulllength human contactin-2 (Figure 1B, GPI-anchored CNTN2) or secreted contactin-2 where the GPI-anchor domain was inactivated by the addition of a V5-epitope tag (Figure 1B, sCNTN2). These constructs were transfected into Chinese Hamster Ovary $(\mathrm{CHO})$ cells and stable $\mathrm{CHO}$ cell clones with high expression of GPI-anchored CNTN2 or sCNTN2, were selected for the experiments 


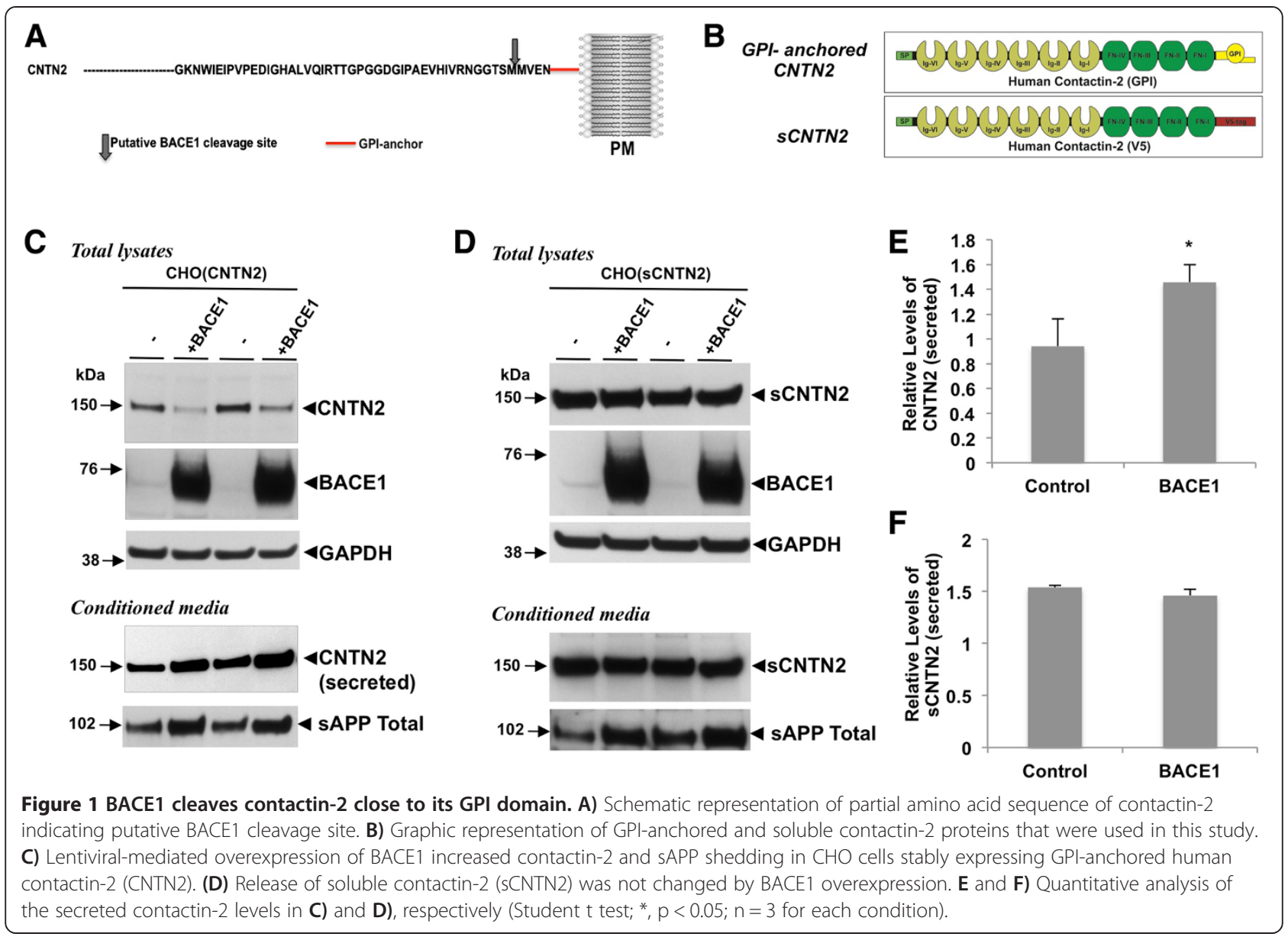

(Additional file 1: Figure S1). As expected, Western blot analysis of the conditioned media using a human contactin-2 antibody revealed a strong increase in the secreted form of contactin-2 in CHO cells with sCNTN2 due to the lack of active GPI-anchor domain (Additional file 1: Figure S1A). Interestingly, we also found a small but consistent release of contactin-2 into cell culture media of $\mathrm{CHO}$ cells with GPI-anchored contactin-2 (Additional file 1: Figure S1B). To explore whether BACE1mediated cleavage regulates contactin-2 release into cell culture media, we coexpressed human BACE1 in $\mathrm{CHO}$ cells with contactin-2 and analyzed contactin-2 levels in total cell lysates and conditioned cell culture media (Figure $1 \mathrm{C}$ and D). BACE1 overexpression increased secreted contactin-2 levels by $\sim 2$ fold in $\mathrm{CHO}$ cells with GPI-anchored contactin-2 (Figure 1C and E). As a negative control, we co-expressed BACE1 in $\mathrm{CHO}$ cells expressing sCNTN2 with the inactive GPI anchor domain (Figure 1D and F). As expected, BACE1 expression did not induce significant changes in soluble contactin-2 levels both in the conditioned media and in the total cell lysate (Figure 1D and F). These data confirm that BACE1 cleaves GPI-anchored contactin-2 and therefore regulates the release of contactin- 2 ectodomain.

\section{Endogenous BACE1 activity regulates contactin-2 cleavage}

As BACE1 enhances GPI-anchored contactin-2 shedding, we next investigated whether contactin- 2 cleavage is also regulated by endogenous BACE1 activity. CHO cells expressing GPI-anchored contactin-2 were treated with BACE1 Inhibitor IV for 4 days and changes in contactin-2 levels were assessed by Western blot analysis. As shown in Figure 2A and B, pharmacological inhibition of endogenous BACE1 activity decreased contactin- 2 levels by $49 \%$ in the conditioned media as compared to the DMSO-treated control cells. We also found that BACE1 Inhibitor treatment dramatically increased total contactin-2 levels in cell lysates (Figure 2A). To confirm that BACE1 Inhibitor treatment blocked endogenous BACE1 activity, we also showed significant reduction in total SAPP levels in the conditioned media (Figure 2A). Finally, contactin-2 cell surface levels were assessed under non-permeabilizing conditions by 

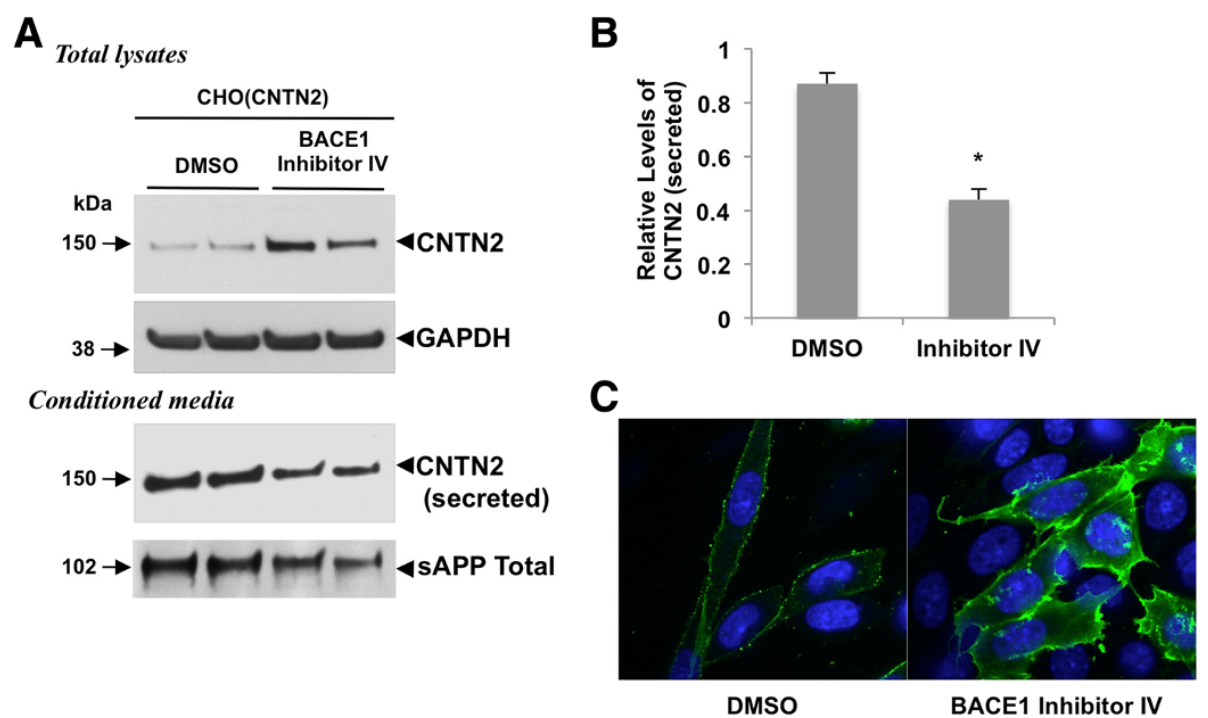

Figure 2 BACE1 inhibition reduces contactin-2 shedding. A) Western blot showing a sharp decrease in contactin-2 levels in CHO(CNTN2) cells treated with BACE1 Inhibitor IV. B) Quantitative analysis of the secreted contactin-2 levels in A) (Student t test; $*, p<0.05 ; n=3$ for each condition). C) Confocal microscopy images of cell surface contactin-2 levels in CHO cells expressing CNTN2. BACE1 Inhibitor IV induced a strong increase in contactin-2 surface levels (green). Nuclear staining with DAPI is shown in blue. Images are taken at identical settings.

immunofluorescence analysis with contactin-2 antibody against extracellular domains. As shown in Figure 2C, inhibition of endogenous BACE1 activity by BACE1 Inhibitor IV treatment markedly reduced contactin-2 shedding and thus significant increased contactin- 2 cell surface levels as compared to the control one. These data clearly demonstrate that endogenous BACE1 activity regulates contactin-2 cleavage, cell surface contactin-2 levels and release of contactin-2 into the cell culture media.

To test whether BACE1 regulates the cleavage of endogenous contactin-2, we next studied contactin-2 shedding in mouse cortical neuronal cultures. Similarly to $\mathrm{CHO}$ cells with GPI-anchored contactin-2, we found that BACE1 inhibitor treatment decreased secreted contactin-2 levels in the conditioned media as compared to DMSO-treated controls (Figure 3A). Quantitation showed an approximately $50 \%$ decrease in secreted contactin-2 levels (Figure 3B). Inhibition of endogenous BACE1 activity was also verified by the decreased total sAPP levels as shown in Figure 3B. Our results demonstrate that endogenous contactin-2 is a substrate for BACE1 and undergoes BACE1-dependent cleavage both in $\mathrm{CHO}$ cells and primary neuronal cultures.

\section{BACE1 cleaves contactin-2 at Met1008-Met1009}

Previously, we have shown that the BACE1 cleavage site mutation 147LM/VI abolished cleavage of the sodium channel $\beta 2$ subunit [28]. Similarly, we now introduced two mutations, 1008-1009MM/AA, into the putative BACE1 cleavage site in contactin-2 (Figures 1A and 4A)

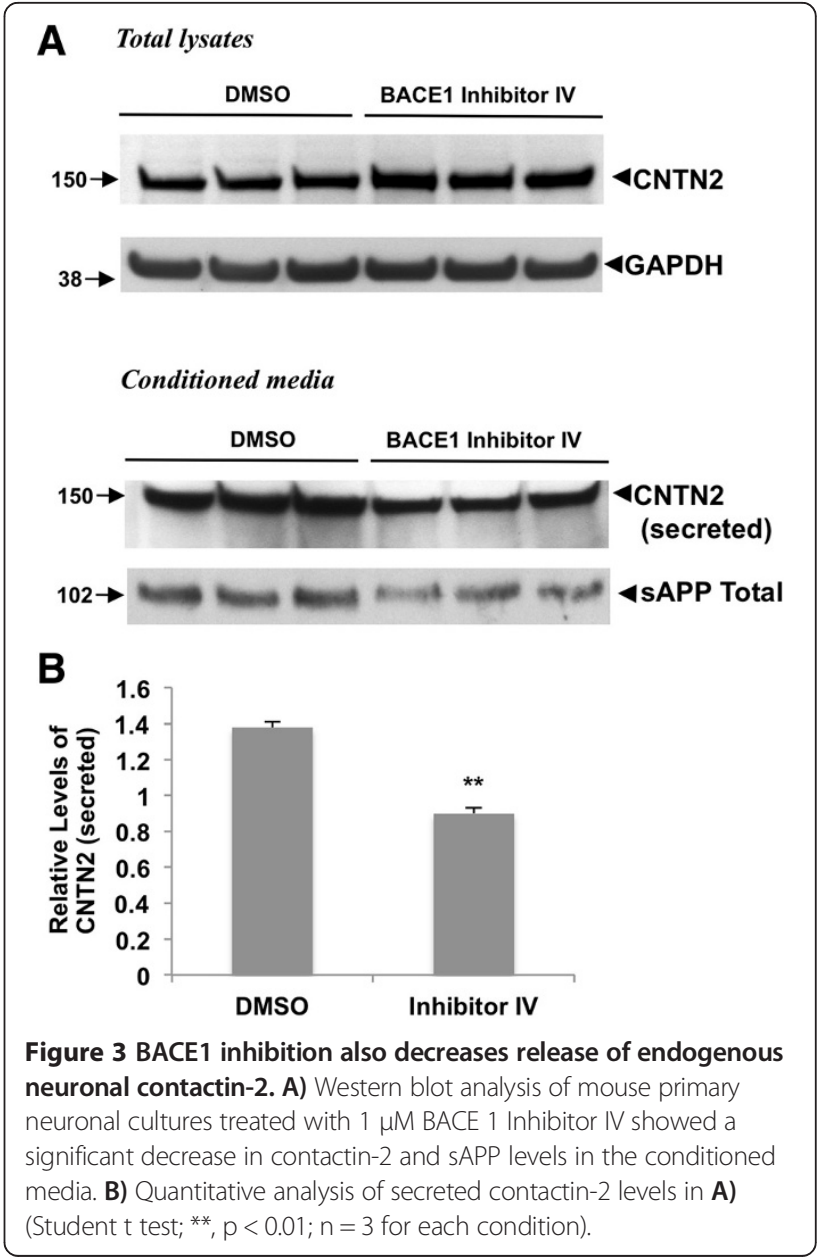



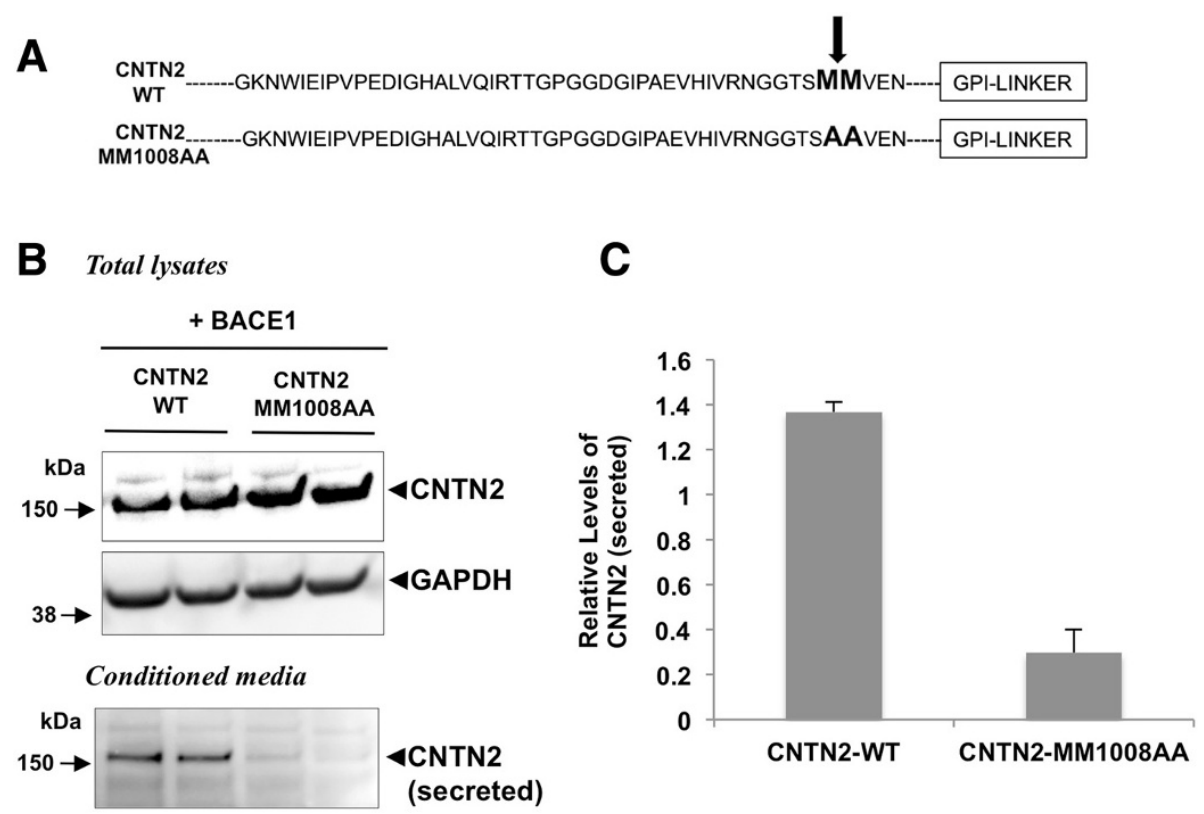

Figure 4 Site-directed mutagenesis of the putative BACE1 cleavage site specifically blocks contactin-2 shedding. A) Partial amino acid sequence of human contactin-2 indicating the putative BACE1 cleavage site. CNTN2-MM1008AA mutations were introduced to block BACE1 cleavage. B) Western blot analysis showing a dramatic reduction in contactin-2 release in the conditioned media of the cells expressing the BACE1-cleavage site mutant contactin-2 (CNTN2-MM1008AA). C) Quantitative analysis of secreted contactin-2 levels in B).

and tested whether these mutations specifically block contactin-2 shedding. To investigate whether the 10081009MM/AA mutations affect BACE1-mediated contactin-2 cleavage, we generated $\mathrm{CHO}$ cells co-expressing BACE1 and wild-type contactin-2 (CNTN2-WT) or mutant contactin-2 (CNTN2-MM1008AA) and analyzed secreted contactin-2 levels in the conditioned media. We found that soluble contactin-2 levels were significantly decreased in CHO cells expressing CNTN2-MM1008AA as compared to CNTN2-WT control cells (Figure 4B). Quantitative analysis showed that soluble contactin-2 levels were decreased by 78\% in CNTN2-MM1008AA cells as compared to wild type control cells (Figure 4C). Together, our data indicate that BACE1-mediated contactin-2 cleavage site is at 1008 Met-1009Met and that this cleavage plays a major role in regulating contactin-2 release in cells.

\section{BACE1 regulates cell surface contactin-2 levels in mouse primary neurons}

We next used cell surface biotinylation of primary mouse neurons to ask whether BACE1 also regulates surface expression of contactin-2 under physiological conditions, in addition to its shedding. To increase BACE1 activity, we infected primary neurons with human BACE1 lentiviral vectors and incubated the cultures for 6 days. BACE1 overexpression dramatically decreased cell surface levels of contactin- 2 while it did not significantly affect surface levels of $\mathrm{N}$-cadherin, a type I membrane protein that is not cleaved by BACE1 (Figure 5A and B). Conversely, when mouse primary neurons were treated with BACE1 Inhibitor IV and subjected to surface biotinylation, we observed a strong increase in contactin- 2 cell surface levels (Figure $5 \mathrm{C}$ and D). Surface levels of APP were concomitantly increased in these neurons (Figure 5C). All together, these data show that BACE1 activity modulates contactin-2 cleavage and thus regulates its surface levels in mouse primary neurons.

\section{Decreased contactin-2 levels in AD brain samples}

Studies have shown that BACE1 activity is significantly increased in late-onset AD brains [29-31]. Previously, we reported that cleavage of the voltage-gated sodium channel $\beta 2$ subunit was increased in $A D$ brain samples, closely correlating with the elevated BACE1 levels [16]. Therefore, we next asked whether contactin-2 cleavage was also increased in the same $\mathrm{AD}$ brain sets with elevated BACE1 levels. Unlike APP or the sodium channel $\beta 2$ subunit, contactin-2 is anchored to the membrane via a GPI domain. Thus, its shedding cannot be assessed by analyzing the levels of its membrane-anchored Cterminal fragments. Instead, we tested whether total levels of contactin-2 are decreased in our AD samples similarly to BACE1 overexpression in our cellular models (Figures 1 and 5). Western blot analysis revealed that contactin-2 levels were generally decreased in $\mathrm{AD}$ brain samples as compared to control age-matched samples (Figure 6A). Quantitative analysis showed a 


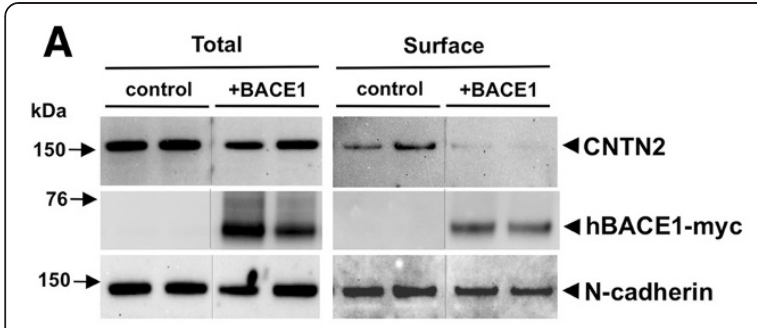

B

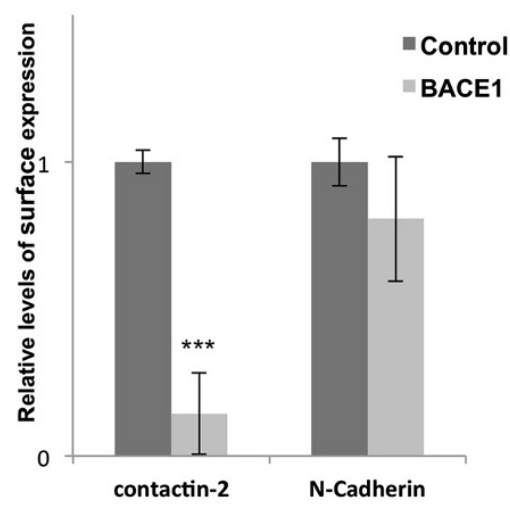

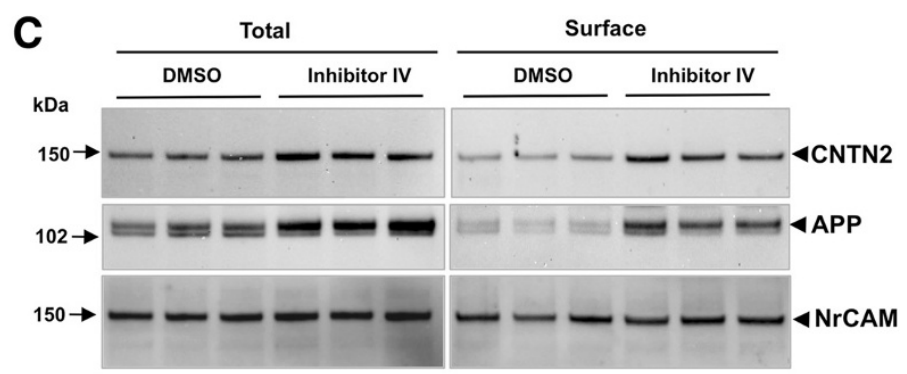

D

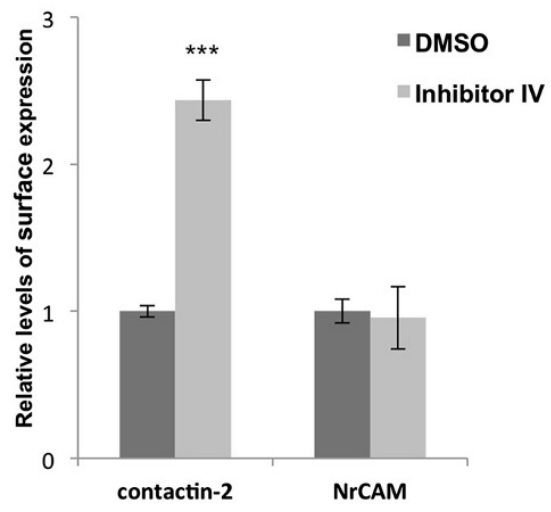

Figure 5 BACE1 regulates surface levels of contactin-2 in mouse primary neuronal cultures. A) Western blot analysis showed that surface levels of contactin-2 were largely decreased by BACE1 overexpression in mouse primary neuronal cultures. B) Quantitative analysis of surface contactin-2 and the control N-cadherin levels in A) (Student $t$ test; ***, $p<0.005 ; n=3$ for each condition). C) Western blot analysis showed that surface levels of contactin-2 were largely increased by BACE1 Inhibitor IV treatments. D) Quantitative analysis of surface contactin-2 and the control NrCAM levels in C). (Student $t$ test; ${ }^{* *}, p<0.005 ; n=3$ for each condition).

significant $\sim 50 \%$ decrease in contactin- 2 in AD brain samples (Figure 6B; $\mathrm{p}<0.01 ; \mathrm{n}=9$ for $\mathrm{AD}, 8$ for non$\mathrm{AD})$. More importantly, decreased contactin-2 levels were closely correlated with BACE1 levels (Figure 6C; $\mathrm{p}=0.032 ; \mathrm{n}=17)$ and even more closely with amyloid plaque density (Figure 6D; $\mathrm{p}=0.0064 ; \mathrm{n}=17$ ). The close correlation of contactin-2 levels with amyloid plaque density may also stem from amyloid-induced elevated presynaptic BACE1 in AD brains [32]. Together, our results indicate that elevated BACE1 activity increases contactin-2 cleavage in human brains with high BACE1 levels.

In this study, we showed that BACE1 activity tightly regulates cell surface contactin-2 levels in $\mathrm{CHO}$ cells and cultured mouse primary neurons by selectively cleaving cell surface contactin-2. Recent studies indicated that BACE1-null neurons display axon guidance defects but the underlying molecular mechanisms are not fully elucidated [12-14]. While the biological activity of the released contactin-2 remains unknown, lack of proper BACE1-mediated cleavage of surface neural adhesion molecules such as contactin-2 may provide an explanation for axon guidance defects observed in BACE1-null mice [13,20]. Since contactin-2 regulates axon guidance through homophilic and heterophilic interactions with other neural adhesion molecules [25,26,33-38], abnormal accumulation of surface contactin-2 by BACE1 knock-down may interfere the proper axon guidance in vivo. In mice, premature early overexpression of contactin-1 (F3/contactin) leads to the reduction in the cerebellar size, granule cell numbers and Purkinje cell maturation [39], which suggests the importance of the precise contactin expression in early brain development. Similarly, Hitt et al. recently proposed that decreased BACE1-mediated shedding of CHL1 may also contribute to axon guidance deficits in BACE1-null neurons [13]. Our findings, together with those of Hitt et al., suggest that lack of proper BACE1mediated shedding of neural adhesion molecules may produce the final phenotype of axon guidance deficits found in BACE1-null neurons. It will be interesting to identify all major neural adhesion molecules mediating the effect of BACE1 on axonal guidance in neural tissues.

Our data in Figure 6 also suggest that elevated BACE1 in brains of $\mathrm{AD}$ patients may also contribute to $\mathrm{AD}$ pathogenesis by decreasing contactin-2 levels and possibly its surface expression. Mice lacking contactin-2 show deficits in neuronal migration (for a subset of cerebella neurons) [40], neurogenesis [41], learning and memory 


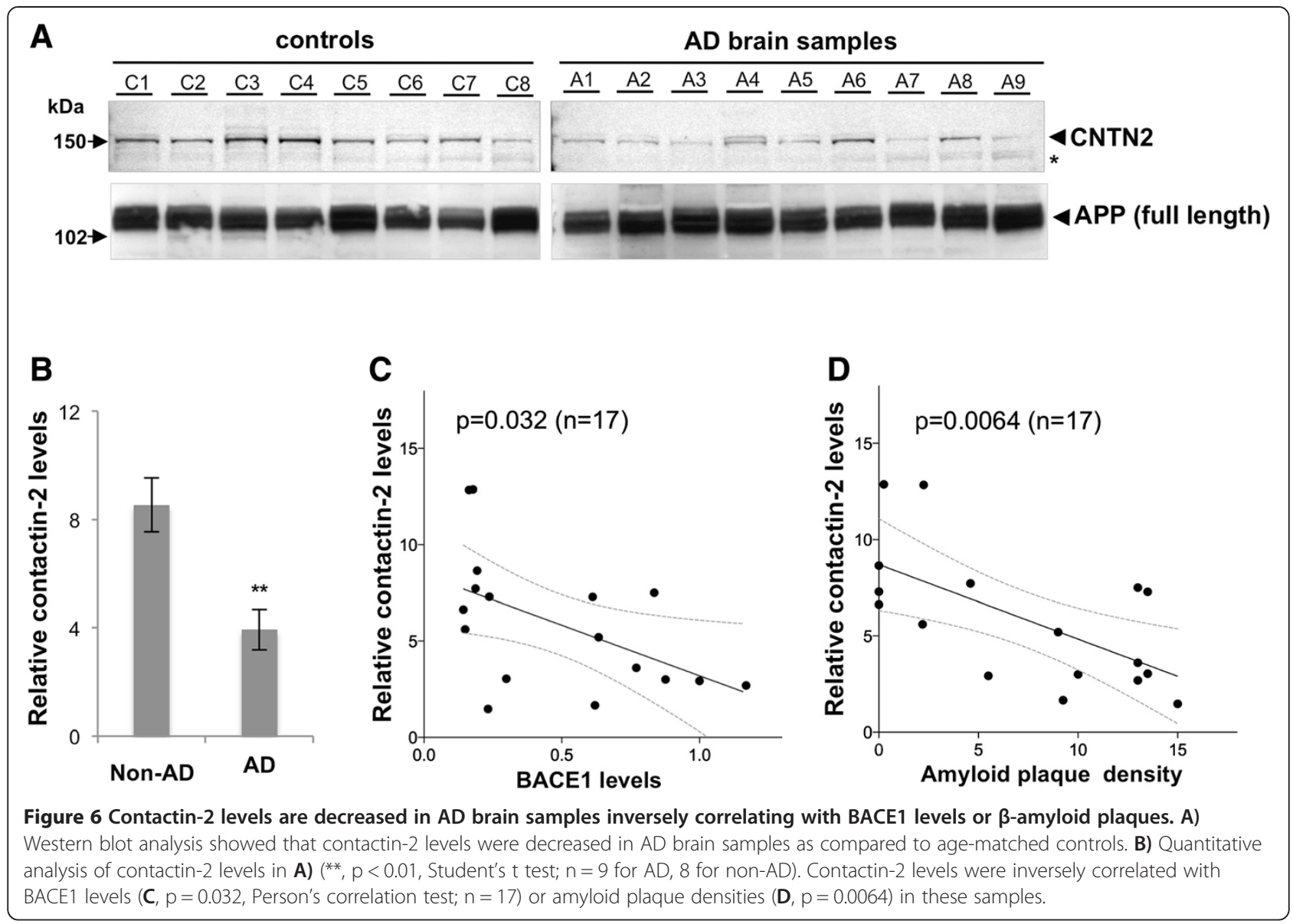

[26] and ion channel clustering [26,42]. Therefore, decreased contactin-2 levels in brains of AD patients may contribute the neuronal deficits through multiple mechanisms. However, further studies will be required to fully characterize the functional consequences of BACE1mediated contactin-2 cleavage in AD pathogenesis as well as its potential side-effects during BACE1 inhibitor therapies currently in clinical trials.

While we were investigating human contactin-2 cleavage in our cellular model systems, two unbiased secretome analyses have been published showing that TAG-1 (mouse contactin-2) ectodomain release is regulated by BACE1 activity in mouse primary neuronal cultures $[19,20]$. Kuhn et al. also confirmed that TAG-1 ectodomain release was significantly decreased in brains of BACE1-null mice [19]. Consistent with these findings, we confirmed that BACE1 activity tightly regulates the release of contactin-2 in mouse primary neuronal cultures (Figure 3). Moreover, we characterized human contactin- 2 cleavage by BACE1 and identified the cleavage site for the first time (Figures 1, 2 and 4). Our surface biotinylation studies also demonstrated that BACE1 activity tightly regulates cell surface contactin-2 levels in cultured mouse primary neurons (Figure 5).
Together, our data show that human and mouse contactin-2 are endogenous substrates for BACE1 and that BACE1-mediated cleavage modulates the surface expression of contactin-2.

\section{Additional file}

Additional file 1: Figure S1. Expression of sCNTN2 and GPI-anchored CNTN2 in CHO cells. Western blot analysis showed the overexpressed sCNTN2 is mostly secreted into the conditioned media (A) while GPI-anchored CNTN2 is mostly in the total lysate fraction (B).

\section{Competing interests}

The authors declare that they have no competing interests.

\section{Authors' contributions}

DMK and DYK designed the study and contributed to the analysis of data. VG, CD, MH, and DYK performed the experiments and collected data. VG, DMK and DYK wrote and revised the manuscript. All authors read and approved the final manuscript.

\section{Acknowledgements}

We would like to thank Dr. Yong Shen (Roskamp Institute, Sarasota, FL) for providing $A D$ and control age-matched brain samples. We also would like to thank Ms. Carmilla Peach, Carolyn C. Sachse and Mr. Manuel T. Gersbacher (Massachusetts General Hospital, Boston, MA) for technical help in this study. This work is supported by grants from the NIA to DMK and DYK. 
Received: 18 October 2013 Accepted: 4 December 2013

Published: 9 January 2014

\section{References}

1. Selkoe DJ: Alzheimer's disease is a synaptic failure. Science 2002, 298(5594):789-791.

2. Sinha S, Anderson JP, Barbour R, Basi GS, Caccavello R, Davis D, Doan M, Dovey HF, Frigon N, Hong J, Jacobson-Croak K, Jewett N, Keim P, Knops J, Lieberburg I, Power M, Tan H, Tatsuno G, Tung J, Schenk D, Seubert P, Suomensaari SM, Wang S, Walker D, Zhao J, McConlogue L, John V: Purification and cloning of amyloid precursor protein beta-secretase from human brain. Nature 1999, 402(6761):537-540

3. Vassar R, Bennett BD, Babu-Khan S, Kahn S, Mendiaz EA, Denis P, Teplow DB, Ross S, Amarante P, Loeloff R, Luo Y, Fisher S, Fuller J, Edenson S, Lile J, Jarosinski MA, Biere AL, Curran E, Burgess T, Louis JC, Collins F, Treanor J, Rogers G, Citron M: Beta-secretase cleavage of Alzheimer's amyloid precursor protein by the transmembrane aspartic protease BACE. Science 1999, 286(5440):735-741.

4. De Strooper B: Aph-1, Pen-2, and Nicastrin with Presenilin generate an active gamma-Secretase complex. Neuron 2003, 38(1):9-12.

5. Vassar R: BACE1: the beta-secretase enzyme in Alzheimer's disease. J Mol Neurosci 2004, 23(1-2):105-114.

6. Cole SL, Vassar R: The Alzheimer's disease beta-secretase enzyme, BACE1. Mol Neurodegener 2007, 2:22.

7. Laird FM, Cai H, Savonenko AV, Farah MH, He K, Melnikova T, Wen H, Chiang HC, Xu G, Koliatsos VE, Borchelt DR, Price DL, Lee HK, Wong PC: BACE1, a major determinant of selective vulnerability of the brain to amyloid-beta amyloidogenesis, is essential for cognitive, emotional, and synaptic functions. J Neurosci 2005, 25(50):11693-11709.

8. Hu X, Hicks CW, He W, Wong P, Macklin WB, Trapp BD, Yan R: Bace1 modulates myelination in the central and peripheral nervous system. Nat Neurosci 2006, 9(12):1520-1525.

9. Willem M, Garratt AN, Novak B, Citron M, Kaufmann S, Rittger A, DeStrooper $B$, Saftig P, Birchmeier C, Haass C: Control of peripheral nerve myelination by the beta-secretase BACE1. Science 2006, 314(5799):664-666.

10. Vassar R, Kovacs DM, Yan R, Wong PC: The beta-secretase enzyme BACE in health and Alzheimer's disease: regulation, cell biology, function, and therapeutic potential. J Neurosci 2009, 29(41):12787-12794.

11. Hu X, Zhou X, He W, Yang J, Xiong W, Wong P, Wilson CG, Yan R: BACE1 deficiency causes altered neuronal activity and neurodegeneration. J Neurosci 2010, 30(26):8819-8829.

12. Rajapaksha TW, Eimer WA, Bozza TC, Vassar R: The Alzheimer's beta-secretase enzyme BACE1 is required for accurate axon guidance of olfactory sensory neurons and normal glomerulus formation in the olfactory bulb. Mol Neurodegener 2011, 6:88.

13. Hitt B, Riordan SM, Kukreja L, Eimer WA, Rajapaksha TW, Vassar R: Beta-Site amyloid precursor protein (APP)-cleaving enzyme 1 (BACE1)-deficient mice exhibit a close homolog of L1 (CHL1) loss-of-function phenotype involving axon guidance defects. J Biol Chem 2012, 287(46):38408-38425.

14. Cao L, Rickenbacher GT, Rodriguez S, Moulia TW, Albers MW: The precision of axon targeting of mouse olfactory sensory neurons requires the BACE1 protease. Sci Rep 2012, 2:231.

15. Kitazume S, Tachida Y, Oka R, Kotani N, Ogawa K, Suzuki M, Dohmae N, Takio K, Saido TC, Hashimoto Y: Characterization of alpha 2,6sialyltransferase cleavage by Alzheimer's beta -secretase (BACE1). J Biol Chem 2003, 278(17):14865-14871.

16. Kim DY, Carey BW, Wang H, Ingano LA, Binshtok AM, Wertz MH, Pettingell WH, He P, Lee VM, Woolf CJ, Kovacs DM: BACE1 regulates voltage-gated sodium channels and neuronal activity. Nat Cell Biol 2007, 9(7):755-764.

17. Hemming ML, Elias JE, Gygi SP, Selkoe DJ: Identification of beta-secretase (BACE1) substrates using quantitative proteomics. PLOS One 2009, 4(12):e8477.

18. Velanac V, Unterbarnscheidt T, Hinrichs W, Gummert MN, Fischer TM, Rossner MJ, Trimarco A, Brivio V, Taveggia C, Willem M, Haass C, Mobius W, Nave KA, Schwab MH: Bace1 processing of NRG1 type III produces a myelin-inducing signal but is not essential for the stimulation of myelination. Glia 2012, 60(2):203-217.

19. Kuhn PH, Koroniak K, Hogl S, Colombo A, Zeitschel U, Willem M, Volbracht C, Schepers U, Imhof A, Hoffmeister A, Haass C, Rossner S, Brase S, Lichtenthaler SF: Secretome protein enrichment identifies physiological BACE1 protease substrates in neurons. EMBO J 2012, 31(14):3157-3168.
20. Zhou L, Barao S, Laga M, Bockstael K, Borgers M, Gijsen H, Annaert W, Moechars D, Mercken M, Gevaert K, De Strooper B: The neural cell adhesion molecules $\mathrm{L} 1$ and $\mathrm{CHL} 1$ are cleaved by BACE1 protease in vivo. J Biol Chem 2012, 287(31):25927-25940.

21. Sachse CC, Kim YH, Agsten M, Huth T, Alzheimer C, Kovacs DM, Kim DY: BACE1 and presenilin/gamma-secretase regulate proteolytic processing of KCNE1 and 2, auxiliary subunits of voltage-gated potassium channels. FASEB J 2013, 27(6):2458-2467.

22. Furley AJ, Morton SB, Manalo D, Karagogeos D, Dodd J, Jessell TM: The axonal glycoprotein TAG-1 is an immunoglobulin superfamily member with neurite outgrowth-promoting activity. Cell 1990, 61(1):157-170.

23. Shimoda $Y$, Watanabe $K$ : Contactins: emerging key roles in the development and function of the nervous system. Cell Adh Migr 2009, 3(1):64-70.

24. Baeriswyl T, Stoeckli ET: Axonin-1/TAG-1 is required for pathfinding of granule cell axons in the developing cerebellum. Neural Dev 2008, 3:7.

25. Wolman MA, Sittaramane VK, Essner JJ, Yost HJ, Chandrasekhar A, Halloran MC: Transient axonal glycoprotein-1 (TAG-1) and laminin-alpha1 regulate dynamic growth cone behaviors and initial axon direction in vivo. Neural Dev 2008, 3:6.

26. Savvaki M, Panagiotaropoulos T, Stamatakis A, Sargiannidou I, Karatzioula P, Watanabe K, Stylianopoulou F, Karagogeos D, Kleopa KA: Impairment of learning and memory in TAG-1 deficient mice associated with shorter CNS internodes and disrupted juxtaparanodes. Mol Cell Neurosci 2008, 39(3):478-490.

27. Bhattacharyya R, Barren C, Kovacs DM: Palmitoylation of amyloid precursor protein regulates amyloidogenic processing in lipid rafts. J Neurosci 2013, 33(27):11169-11183.

28. Gersbacher MT, Kim DY, Bhattacharyya R, Kovacs DM: Identification of BACE1 cleavage sites in human voltage-gated sodium channel beta 2 subunit. Mol Neurodegener 2010, 5:61.

29. Fukumoto $H$, Cheung BS, Hyman BT, Irizarry MC: Beta-secretase protein and activity are increased in the neocortex in Alzheimer disease. Arch Neurol 2002, 59(9):1381-1389.

30. Tyler SJ, Dawbarn D, Wilcock GK, Allen SJ: Alpha- and beta-secretase: profound changes in Alzheimer's disease. Biochem Biophys Res Commun 2002, 299(3):373-376.

31. Yang LB, Lindholm $K$, Yan R, Citron M, Xia W, Yang XL, Beach $T$, Sue L, Wong P, Price D, Li R, Shen Y: Elevated beta-secretase expression and enzymatic activity detected in sporadic Alzheimer disease. Nat Med 2003, 9 (1):3-4.

32. Zhao J, Fu Y, Yasvoina M, Shao P, Hitt B, O'Connor T, Logan S, Maus E, Citron $M$, Berry $R$, Binder $L$, Vassar R: Beta-site amyloid precursor protein cleaving enzyme 1 levels become elevated in neurons around amyloid plaques: implications for Alzheimer's disease pathogenesis. J Neurosci 2007, 27(14):3639-3649.

33. Fitzli D, Stoeckli ET, Kunz S, Siribour K, Rader C, Kunz B, Kozlov SV, Buchstaller A, Lane RP, Suter DM, Dreyer WJ, Sonderegger P: A direct interaction of axonin-1 with $\mathrm{NgCAM}$-related cell adhesion molecule (NrCAM) results in guidance, but not growth of commissural axons. J Cell Biol 2000, 149(4):951-968.

34. Stoeckli ET, Ziegler U, Bleiker AJ, Groscurth P, Sonderegger P: Clustering and functional cooperation of $\mathrm{Ng}-\mathrm{CAM}$ and axonin-1 in the substratumcontact area of growth cones. Dev Bio/ 1996, 177(1):15-29.

35. Felsenfeld DP, Hynes MA, Skoler KM, Furley AJ, Jessell TM: TAG-1 can mediate homophilic binding, but neurite outgrowth on TAG-1 requires an L1-like molecule and beta 1 integrins. Neuron 1994, 12(3):675-690.

36. Rader C, Stoeckli ET, Ziegler U, Osterwalder T, Kunz B, Sonderegger P: Cell-cell adhesion by homophilic interaction of the neuronal recognition molecule axonin-1. Eur J Biochem 1993, 215(1):133-141.

37. Lin JF, Pan HC, Ma LP, Shen YQ, Schachner M: The cell neural adhesion molecule contactin-2 (TAG-1) is beneficial for functional recovery after spinal cord injury in adult zebrafish. PLoS One 2012, 7(12):e52376.

38. Perrin FE, Rathjen FG, Stoeckli ET: Distinct subpopulations of sensory afferents require F11 or axonin-1 for growth to their target layers within the spinal cord of the chick. Neuron 2001, 30(3):707-723.

39. Bizzoca A, Virgintino D, Lorusso L, Buttiglione M, Yoshida L, Polizzi A, Tattoli M, Cagiano R, Rossi F, Kozlov S, Furley A, Gennarini G: Transgenic mice expressing F3/contactin from the TAG-1 promoter exhibit developmentally regulated changes in the differentiation of cerebellar neurons. Development 2003, 130(1):29-43. 
40. Denaxa M, Kyriakopoulou K, Theodorakis K, Trichas G, Vidaki M, Takeda Y, Watanabe K, Karagogeos D: The adhesion molecule TAG-1 is required for proper migration of the superficial migratory stream in the medulla but not of cortical interneurons. Dev Biol 2005, 288(1):87-99.

41. Ma QH, Futagawa T, Yang WL, Jiang XD, Zeng L, Takeda Y, Xu RX, Bagnard D, Schachner M, Furley AJ, Karagogeos D, Watanabe K, Dawe GS, Xiao ZC: A TAG1-APP signalling pathway through Fe65 negatively modulates neurogenesis. Nat Cell Biol 2008, 10(3):283-294.

42. Poliak S, Salomon D, Elhanany H, Sabanay H, Kiernan B, Pevny L, Stewart CL, Xu X, Chiu SY, Shrager P, Furley AJ, Peles E: Juxtaparanodal clustering of Shaker-like $\mathrm{K}+$ channels in myelinated axons depends on Caspr2 and TAG-1. J Cell Biol 2003, 162(6):1149-1160.

doi:10.1186/1750-1326-9-4

Cite this article as: Gautam et al:: BACE1 activity regulates cell surface contactin-2 levels. Molecular Neurodegeneration 2014 9:4.

\section{Submit your next manuscript to BioMed Central and take full advantage of:}

- Convenient online submission

- Thorough peer review

- No space constraints or color figure charges

- Immediate publication on acceptance

- Inclusion in PubMed, CAS, Scopus and Google Scholar

- Research which is freely available for redistribution 